\title{
PENGARUH DYMETIL ESTER PADA BIOSOLAR TERHADAP UNJUK KERJA MOTOR DIESEL SATU SILINDER PADA SUHU PEMANASAN BAHAN BAKAR $95{ }^{\circ} \mathrm{C}$
}

\author{
Yusup Nur Rohmat ${ }^{1}$, Kusnandar², Rizki Adila Saputro ${ }^{3}$ \\ ${ }^{1,2}$ Politeknik Negeri Indramayu, STT Wiworotomo Purwokerto ${ }^{3}$ \\ ${ }^{1,2}$ Jl. Raya Lohbener Lama No.08, J1. Semingkir No. 01 Purwokerto $^{3}$ \\ E-mail : yusupnurrohmat@gmail.com ${ }^{1}$, kusnandar11@gmail.com²,rizkiadilasaputro22@gmail.com
}

\begin{abstract}
Abstrak
Menipisnya cadangan minyak bumi membuat munculnya berbagai macam energi alternatif, salah satunya adalah biodiesel. Biodiesel adalah ester asam lemak yang berasal dari minyak nabati atau hewani melalui reaksi transesterifikasi atau esterifikasi. Tujuan penelitian ini dilakukan pengujian untuk mengetahui pengaruh penggunaan campuran bahan bakar biodiesel jelantah dengan pemanasan $95^{\circ} \mathrm{C}$ terhadap daya, torsi dan Sfc. Pengujian dilakukan dengan memberikan beban lampu dari 200 - 3200 watt pada variasi volume bahan bakar biodiesel sebesar 30\%, 40\% dan 50\%. Metode penelitian yang digunakan menggunakan analisa deskriptif dimana hasil penelitian digambarkan dan di deskripsikan berdasarkan hasil penelitian. Dari hasil pengujian menghasilkan penambahan bahan bakar biodiesel Jelantah berpengaruh terhadap daya, torsi dan Sfc yang dihasilkan motor diesel.
\end{abstract}

Kata Kunci: Pemanasan Bahan Bakar, Biodiesel Jelantah, Performance

\begin{abstract}
The depletion of petroleum reserves makes the emergence of a variety of alternative energy, one of which is Biodiesel. Biodiesel is a fatty acid ester derived from vegetable oil or animal by transesterification or esterification reaction. The purpose of this study was conducted to determine the effect of the use of fuel mixture of biodiesel jelantah with heating 950C to power, torque and SfC. The test is done by loading the lamp load from 200 - 3200 watt on variation of biodiesel fuel volume by 30\%, 40\% and 50\%. The research method used is descriptive analysis where the result of research is described and described based on research result. From the test results resulted in the addition of biodiesel jelantah fuel effect on power, torque and Sfc generated diesel motor.
\end{abstract}

Keywords: Heating Fuel, Wasted Biodiesel, Performance

\section{PENDAHULUAN}

Menipisnya cadangan minyak bumi membuat munculnya berbagai macam energi alternatif, salah satunya adalah biodiesel. Biodiesel adalah ester asam lemak yang berasal dari minyak nabati atau hewani melalui reaksi transesterifikasi atau esterifikasi dan digunakan sebagai bahan bakar diesel (Darnoko dan Cheryan, 2007).

Biodiesel merupakan bahan yang sangat potensial digunakan sebagai pengganti bahan bakar diesel. Hal ini disebabkan karena bahan bakunya yang berasal dari minyak nabati, dapat diperbaharui, dapat dihasilkan secara periodic dan mudah diperoleh. Selain itu harganya relatif stabil dan produksinya mudah disesuaikan dengan kebutuhan. Biodiesel juga merupakan bahan bakar yang ramah lingkungan, tidak mengandung belerang sehingga dapat mengurangi kerusakan lingkungan yang diakibatkan oleh hujan asam (rain acid). Penggunaan minyak goreng bekas sebagai bahan baku memberikan beberapa keuntungan, diantaranya: harga murah, mudah didapat dan dapat menanggulangi pencemaran yang disebabkan oleh limbah minyak goreng bekas.

Berbagai penelitian tentang pengujian langsung biodiesel sebagai bahan bakar motor diesel sudah dilakukan menggunakan biodiesel yang berasal dari minyak jarak pagar dan minyak kelapa sebagai bahan baku biodisel juga sudah diujikan pada motor diesel. Pemerintah melalui pertamina juga sudah mengkomersilkan biodiesel, tetapi belum bentuk biodiesel murni. Biodiesel yang dikomersilkan berupa campuran biodisel dengan solar yang dikenal dengan istilah biosolar. Kandungan biodiesel yang terdapat dalam biosolar masih $5 \%$ volum (B5) yang terdapat pada peraturan presiden nomor 5 tahun 2006 tentang kebijakan energi.

Biodiesel dikenal sebagai bahan bakar yang ramah lingkungan dan dapat diperbarui. Biodiesel biasanya dibuat dengan transesterifikasi minyak tumbuhan atau lemak hewan dengan methanol atau etanol (Huaping, 2006). Biodiesel yang diproduksi dari minyak tumbuhan 
atau lemak hewan biasanya lebih mahal dibanding bahan bakar diesel konvensional dari minyak bumi (Ozbay, 2008). Mengingat hal tersebut maka biodiesel dapat saja dibuat dari minyak nabati yang tidak harus baru, seperti minyak jelantah (minyak bekas penggorengan).

Biodiesel adalah salah satu energi alternatif yang secara umum densitas dan viskositasnya lebih besar dari pada minyak solar sedangkan nilai kalornya lebih rendah. Viskositas merupakan parameter penting untuk penginjeksian, pencampuran dengan udara, dan pembakaran sempurna. Besarnya viskositas menyebabkan pembakaran kurang sempurna, salah satu alternatif agar pembakaran menjadi sempurna, maka biodiesel diturunkan viskositasnya dengan jalan dipanaskan.

Mendasarkan pada penelitian (Grahan, 2012, Pengaruh Pemanasan Bahan Bakar terhadap Unjuk Kerja Motor Diesel Silinder Tunggal Berbahan Bakar biodiesel, skripsi, Sekolah Tinggi Teknik Wiworotomo, Purwokerto) pengujian tersebut dilakukan secara eksperimental pada motor diesel silinder tunggal berbahan bakar biodiesel minyak kelapa dengan meningkatkan temperatur bahan bakar sebesar $85^{\circ} \mathrm{C}$ dan $95^{\circ} \mathrm{C}$ sebelum injector dan didapatkan hasil daya, torsi dan $B M E P$ maksimal dimiliki oleh pemanasan dengan temperatur $95^{\circ} \mathrm{C}$. Maka penyusun mencoba meneliti dan mengaplikasikan variasi campuran bahan bakar biosolar dengan biodiesel jelantah (dymetil ester) dan dipanaskan melalui pipa tekanan tinggi dengan suhu pemanasan konstan $95^{\circ} \mathrm{C}$ guna mengurangi nilai viskositas dari campuran bahan bakar tersebut. Sehingga diharapkan penginjeksian, pencampuran dengan udara, dan pembakaran sempurna.

\section{TINJAUAN PUSTAKA}

\section{A. Kajian Pustaka}

Mukondar, 2012 meneliti Analisa Pengaruh Pemanasan Bahan Bakar Terhadap Unjuk Kerja Motor Diesel. Pengujian ini dilakukan dengan menggunakan panel beban lampu dan variasi beban lampu mulai dari 600 Watt sampai dengan 2800 Watt pada putaran motor konstan sebesar $1500 \mathrm{rpm}$ atau $50 \mathrm{~Hz}$ dengan bahan bakar biosolar. Pada penelitian ini didapatkan hasil bahwa daya meningkat sebesar $3,5 \%$ pada temperatur $55^{\circ} \mathrm{C}$ dan pada temperatur $65^{\circ} \mathrm{C}$ sebesar $3,8 \%$ dari kondisi standart serta torsi meningkat sebesar $3,5 \%$ pada temperatur $55^{\circ} \mathrm{C}$ dan pada suhu $65^{\circ} \mathrm{C}$ torsi meningkat sebesar $3,84 \%$ dari kondisi standart serta konsumsi bahan bakar menurun sebesar $3,5 \%$ pada temperatur $55^{\circ} \mathrm{C}$ dan pada temperatur $65^{\circ} \mathrm{C}$ menurun sebesar $29,4 \%$ dari kondisi standar.

Eka Bagus Syahrudin, 2014 meniliti pencampuran bahan bakar solar dengan minyak jelantah untuk mengetahui seberapa besar pengaruh terhadap unjuk kerja motor diesel 1 silinder dibandingkan dengan solar murni dengan menggunakan metode eksperimental dengan prosentase campuran minyak jelantah 50\%, 60\% dan 70\% pada 1 liter solar. Hasil penelitian besarnya torsi yang dihasilkan dari pengujian biodiesel minyak jelantah maka diperoleh hasil bahwa torsi paling tinggi diperoleh pada kondisi standart sebesar 13,178 $\mathrm{Nm}$ pada beban 2400
Watt, campuran minyak jelantah $50 \%$ sebesar $12,840 \mathrm{Nm}$, campuran minyak jelantah $60 \%$ sebesar $12,630 \mathrm{Nm}$ dan campuran minyak jelantah $70 \%$ sebesar 11,101 . Selanjutnya besarnya daya yang dihasilkan dari penggunaan biodiesel minyak jelantah pada motor daya terbesar dihasilkan saat pengujian standar menunjukkan daya 2.069 Watt pada beban 2.400 Watt, campuran minyak jelantah $60 \%$ sebesar 1.983 Watt pada beban 2.400 Watt, campuran minyak jelantah 50\% sebesar 2.016 Watt pada beban 2.400 Watt, campuran minyak jelantah $70 \%$ sebesar 1.905 Watt pada beban 2200 Watt. Konsumsi bahan bakar untuk biodiesel minyak jelantah terendah pada campuran minyak jelantah $50 \%$ sebesar 0,452 $\mathrm{kg} / \mathrm{kWh}$, campuran $60 \%$ sebesar $0,455 \mathrm{~kg} / \mathrm{kWh}$, standar sebesar $0,471 \mathrm{~kg} / \mathrm{kWh}$ dan campuran $70 \%$ sebesar 0,481 $\mathrm{kg} / \mathrm{kWh}$. Dalam penelitian viskositas campuran solar dengan minyak jelantah sangat berpengaruh, karena viskositas minyak jelantah yang kental hasil daya dan torsi menurun dari standart. Oleh karena itu sebaiknya dipasang pemanas yang dipasang pada pipa delivery baik sebelum pompa injeksi ataupun sesudah pompa injeksi agar viskositas dari campuran minyak jelantah tidak terlalu kental.

\section{B. Kajian Teori}

Proses ini terjadi pada motor diesel 4 langkah dengan putaran rendah. Pada motor diesel yang dihisap bukan campuran udara dan bahan bakar, melainkan hanya udara saja. Sesaat sebelum akhir kompresi, bahan bakar disemprotkan dalam bentuk kabut ke dalam silinder. Bahan bakar ini terbakar karena suhu udara yang tinggi. Suhu udara yang tinggi diperoleh karena adanya kompresi adiabatik. Ketika bahan bakar disemprotkan memperoleh suhu yang tinggi dari titik nyala bahan bakar tersebut. Agar bahan bakar dan udara dapat bercampur secara homogen, maka gerakan udara di dalam silinder harus merupakan aliran turbulen. Pembakarannya terjadi pada tekanan tetap.
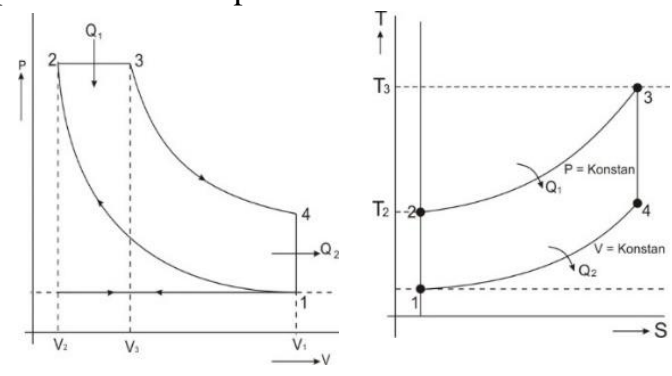

Gambar 1. Diagram P-V dan T-S (Tim Fakultas Teknik, 2003)

Tabel 1. Keterangan Pada Diagram P-V

\begin{tabular}{|c|l|}
\hline Proses & \multicolumn{1}{|c|}{ Keterangan } \\
\hline 0 ke 1 & Proses penghisapan pada tekanan konstan (isobaric) \\
\hline 1 ke 2 & Proses kompresi secara adiabatik/isentropic \\
\hline 2 ke 3 & Proses pemasukan kalor pada tekanan konstan \\
\hline 3 ke 4 & Proses ekspansi secara adiabatic \\
\hline 4 ke 1 & Proses pembuangan kalor pada volume konstan \\
\hline Q1 & Proses pemasukan kalor pada tekanan konstan \\
\hline Q2 & Proses pembuangan kalor pada volume konstan (isobaric) \\
\hline
\end{tabular}


Effisiensi panas dari suatu mesin adalah perbandingan panas yangdisediakan dengan panas yang dirubah menjadi kerja efektif. Bila semua panas yang timbul pada saat pembakaran dapat berubah menjadi kerja efektif dalam silinder, dikatakan efisiensi panas $100 \%$. Bila jumlah panas dari pembakaran disebut $\mathrm{Q}_{1}$ Kkal dan kerugian panas pada dinding silinder adalah $\mathrm{Q}_{2}$ Kkal, maka :

$$
\begin{aligned}
& \text { Efisiensi panas }(\text { nth })=\frac{Q 1-Q 2}{Q 2}=1-\frac{Q 2}{Q 1} \\
& \mathrm{Q} 2=\mathrm{G} \cdot \mathrm{Cv}(\mathrm{T} 4-\mathrm{T} 1) \\
& \mathrm{Q} 1=\mathrm{G} . \mathrm{Cv}(\mathrm{T} 3-\mathrm{T} 2) \\
& \text { nth }=1-\frac{\text { G.Cv }(\mathrm{T} 4-\mathrm{T} 1)}{\mathrm{G} \cdot \mathrm{Cv}(\mathrm{T} 3-\mathrm{T} 2)}=1-\frac{T 4-T 1}{T 3-T 2} \\
& \text { Dimana }: \frac{1}{K}=\frac{C v}{C p} \\
& \frac{\mathrm{T} 1}{\mathrm{~T} 2}=\left(\frac{\mathrm{V} 2}{\mathrm{~V} 1}\right)^{K-1} ; \mathrm{T} 1=\left(\frac{1}{\mathrm{C}}\right)^{K-1} \cdot \mathrm{T} 2 \\
& \frac{\mathrm{T} 3}{\mathrm{~T} 2}=\frac{\mathrm{V} 3}{\mathrm{~V} 2}=>\mathrm{T} 3=\frac{\mathrm{V} 3}{\mathrm{~V} 2} \cdot \mathrm{T} 2 \\
& =>\mathrm{T} 3=\varepsilon . \mathrm{T} 2 \\
& \mathrm{~T} 4-\mathrm{T} 1=\frac{1}{C^{K-1}}\left(\mathcal{E}^{K}-1\right) \mathrm{T} 2 \\
& \mathrm{~T} 3-\mathrm{T} 2=(\Sigma-1) \mathrm{T} 2
\end{aligned}
$$

Jadi efisiensi panas (rendemen thermis)

$$
\begin{gathered}
\text { nth }=\frac{\left(\Sigma^{K} \mathrm{~T} 2\right)}{K \cdot C^{K}-1\left(\Sigma^{K}-1\right) \mathrm{T} 2} \\
\text { nth }=\frac{\left(\Sigma^{K}-1\right)}{K \cdot C^{K}-1\left(\Sigma^{K}-1\right)} \\
\text { nth }=\frac{\Sigma^{K}-1}{C^{K-1} K(\Sigma-1)}
\end{gathered}
$$

Jika jumlah bahan bakar terpakai adalah Gbb Kg/jam, dan nilai kalor bawah bahan bakar adalah $\mathrm{Hb} \mathrm{Kcal} / \mathrm{kg}$, maka efisiensi termal efektif adalah :

nte $=\frac{N e \times 632}{G b b \times H b} \quad$ atau $\quad$ nte $=\frac{632}{b e H b}$

maka untuk be $=0,154 \mathrm{Kg} / \mathrm{Ps}$ jam dan

nte $=\frac{632}{0,154 \times 10000}=0,41$

$$
\mathrm{Hb}=10000 \mathrm{Kcal} / \mathrm{Kg}
$$

nte $=0,377$ untuk momoen putar maksimum

nte $=0,386$ sebagai efisiensi maksimum

Berdasarkan hasil perhitungan harga efisiensi termal tersebut diatas, maka efesiensi termal berkisar pada harga $40 \%$. Jika efisiensi mekanis diperkirakan $80 \%$, maka efisiensi termal indikatornya adalah $50 \%$ menurut perhitungan dimuka.

Dimana :

be = pemakaian bahan bakar spesifikasi, minimal 168 gr/Ps jam pada 1500 rpm, 168 gr/Ps jam pada $2000 \mathrm{rpm}$.

Gbb = jumlah bahan bakar terpakai $(\mathrm{Kg} / \mathrm{jam})$

$\mathrm{Hb}=$ nilai kalor bahan bakar (Kcal/jam)

$\mathrm{Pe}=$ tekanan efektif rata-rata $\left(\mathrm{Kg} / \mathrm{cm}^{2}\right), 7,35 \mathrm{Kg} / \mathrm{cm}^{2}$ pada putaran $2000 \mathrm{rpm}, 8,40 \mathrm{Kg} / \mathrm{cm}^{2}$ pada putaran $2100 \mathrm{rpm}$.

nte $=$ efisiensi termal/ rendemen thermis

$1 \mathrm{PS}=632 \mathrm{Kcal} / \mathrm{jam}$

\section{III.METODE}

Metodologi penelitian merupakan suatu cara untuk memperoleh pengetahuan atau pemecahan masalah secara sistematik dengan menggunakan metode ilmiah yang dikaji dalam bentuk penelitian.

\section{A. Desain Penelitian}

Desain penelitian yang digunakan adalah eksperimental. Khusus dalam penelitian ini menggunakan pemanasan bahan bakar temperature $95^{\circ} \mathrm{C}$ sebelum injektor dengan memvariasikan campuran biosolar dengan biodiesel minyak jelantah (dymetil ester) $30 \%$, 40\%, 50\% dan motor diesel sebagai objek penelitian, dengan menekankan pada subjek pengukuran daya, torsi serta konsumsi bahan bakar spesific (sfc).

\section{B. Variabel Penelitian.}

1. Variabel Bebas

Variabel bebas adalah kondisi yang mempengaruhi munculnya suatu gejala. Dalam hal ini dapat dikatakan bahwa variabel bebas merupakan variasi yang sengaja dipelajari terhadap variabel terikat. Variabel bebas dalam penelitian ini adalah variasi campuran bahan bakar :

a. Standart biosolar.

b. Biosolar dengan campuran biodiesel minyak jelantah $30 \%$

c. Biosolar dengan campuran biodiesel minyak jelantah $40 \%$

d. Biosolar dicampur dengan biodiesel minyak jelantah $50 \%$

\section{Variabel terikat}

Variabel terikat adalah himpunan sejumlah gejala yang memiliki pula sejumlah aspek atau unsur didalamnya yang berfungsi menerima atau menyesuaikan diri dengan kondisi lain, yang disebut variable bebas. Variabel terikat pada penelitian ini adalah :

a. Putaran motor pada rpm $1500( \pm 50 \mathrm{~Hz})$.

b. Bahan bakar yang digunakan pada penelitian ini adalah biosolar dan biodiesel minyak jelantah (dymetil ester).

c. Pemanasan bahan bakar dilakukan pada pipa tekanan tinggi dengan suhu $95^{\circ} \mathrm{C}$.

d. Uji unjuk kerja motor diesel silinder tunggal dengan melihat pada besarnya torsi, daya, serta konsumsi bahan bakar spesific $(s f c)$.

\section{Variabel kontrol}


Variabel kontrol adalah himpunan sejumlah gejala yang memiliki berbagai aspek atau unsur didalamnya yang berfungsi untuk mengendalikan agar variabel terikat yang muncul bukan karena variabel lain, tetapi benar-benar karena variabel bebas tertentu. Pengendalian variabel ini dimaksudkan agar tidak merubah atau menghilangkan variabel bebas yang akan diungkap pengaruhnya. Dengan kata lain kontrol yang dilakukan terhadap variabel ini akan menghasilkan variabel terikat murni. Variabel kontrol pada penelitian ini adalah kondisi standar motor diesel silinder tunggal pada putaran $1500 \mathrm{Rpm}$ dengan variasi pembebanan dari mulai 200 Watt sampai 3200 Watt dengan interval $200 \mathrm{~W}$.

\section{HASIL DAN PEMBAHASAN}

\section{A. Analisa dan Pembahasan}

Data adalah hasil yang diperoleh dari penelitian, datadata tersebut berupa angka-angka yang menunjukan berapa harga atau nilai dari masing-masing perlakuan. Angka-angka tersebut meliputi nilai dari daya, torsi dan konsumsi bahan bakar spesific (sfc).

Pada proses pengambilan data penulis melaksanakan penelitian dengan menggunakan alat-alat yang sudah di persiapkan sebelumnya. Dari hasil pengujian Torsi dilakukan perhitungan Konsumsi bahan bakar spesific (Sfc). Setelah mendapatkan data-data yang diperlukan langkah selanjutnya adalah melakukan proses analisa hasil penelitian.

1. Hubungan daya dan beban (Watt)

Berdasarkan hasil pengujian Daya sebagai pengujian beban pada pemanasan bahan bakar $95^{\circ} \mathrm{C}$ dapat dibuat grafik hubungan Daya dan beban pengujian, sebagai berikut :

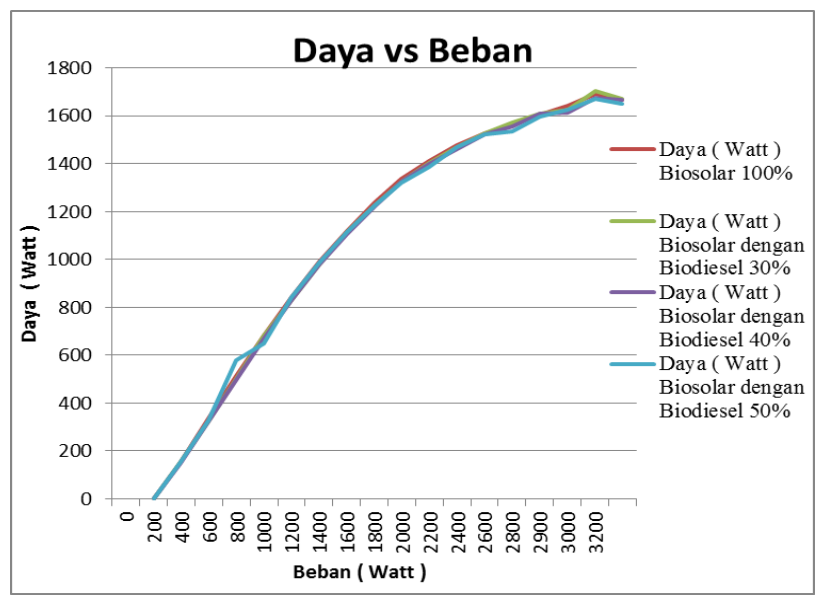

Gambar 2. Grafik Hubungan Daya dan Beban

Berdasarkan grafik hasil pengujian pada variasi bahan bakar dengan pemanasan bahan bakar $95^{\circ} \mathrm{C}$ dapat menghasilkan Daya rata - rata sebagai berikut :

a) Pada pengujian bahan bakar biosolar murni dengan pemanasan bahan bakar $95^{\circ} \mathrm{C}$ menghasilkan Daya rata - rata sebesar 1131,32 Watt.

b) Pada pengujian biosolar dengan variasi biodiesel jelantah 30\% menghasilkan Daya rata - rata sebesar 1127,37 Watt. Pada prosentase biodiesel jelantah $30 \%$ terjadi penurunan Daya hasil pengujian dibandingkan kondisi bahan bakar biosolar murni sebesar 0,349\%. Turunnya Daya hasil pengujian pada prosentase $30 \%$ disebabkan adanya tambahan biodiesel jelantah sehingga menurunkan kualitas bahan bakar.

\section{Hubungan Torsi dan Beban}

Berdasarkan tabel hasil pengujian Torsi sebagai pengujian beban pada pemanasan bahan bakar $95^{\circ} \mathrm{C}$ dapat dibuat grafik hubungan Torsi dan beban pengujian, sebagai berikut :

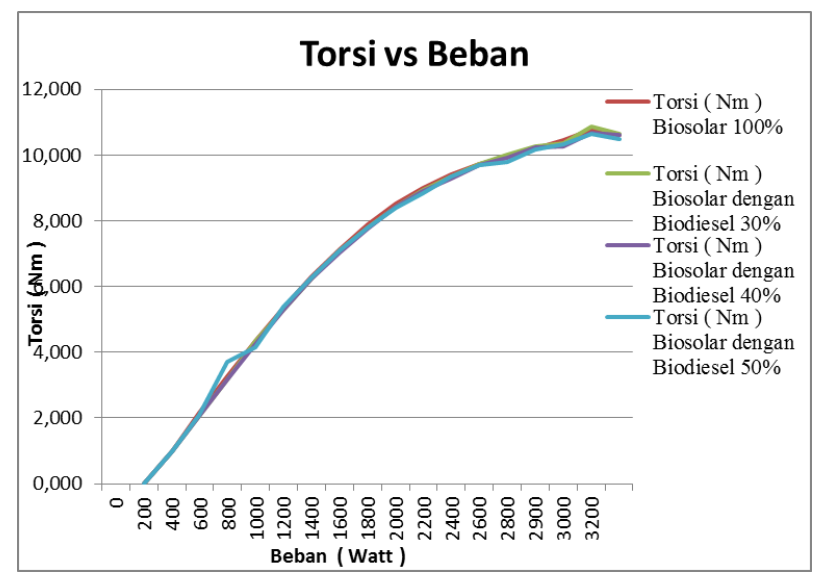

Gambar 3. Grafik Hubungan Torsi dan Beban

Berdasarkan grafik hasil pengujian pada variasi bahan bakar dengan pemanasan bahan bakar $95^{\circ} \mathrm{C}$ prosentase biodiesel jelantah pada bahan bakar dapat menghasilkan Torsi maksimal sebagai berikut :

a) Pada pengujian bahan bakar biosolar murni menghasilkan Torsi rata - rata sebesar 7,21 Nm.

b) Pada pengujian biosolar dengan variasi biodiesel jelantah 30\% menghasilkan Torsi rata - rata sebesar 7,18 Nm. Pada prosentase biodiesel jelantah 30\% terjadi penurunan Torsi hasil pengujian sebesar $0,349 \%$. Penurunan Torsi hasil pengujian diakibatkan prosentase campuran biodiesel yang mengakibatkan menurunnya kualitas bahan bakar.

c) Pada pengujian biosolar dengan variasi biodiesel jelantah $40 \%$ menghasilkan Torsi rata - rata sebesar $7,13 \mathrm{Nm}$. Pada prosentase biodiesel $40 \%$ terjadi penurunan Torsi hasil pengujian sebesar $1,010 \%$. Penurunan Torsi hasil pengujian diakibatkan prosentase biodiesel yang terlalu banyak mengakibatkan menurunnya kualitas bahan bakar.

d) Pada pengujian biosolar dengan variasi biodiesel jelantah $50 \%$ menghasilkan Torsi rata - rata sebesar $7,15 \mathrm{Nm}$. Pada prosentase biodiesel $50 \%$ terjadi penurunan Torsi hasil pengujian sebesar $0,758 \%$. Penurusan Torsi hasil pengujian diakibatkan prosentase biodiesel yang terlalu banyak mengakibatkan menurunnya kualitas bahan bakar.

Pembahasan

Berdasarkan grafik hubungan Torsi dan Beban diperoleh Torsi rata - rata pada penggunaan bahan bakar biosolar murni sebesar 7,21 Nm. Torsi terbesar penggunaan bahan bakar biodiesel jelantah 30\% sebesar 7,18 Nm. Pada penggunaan bahan bakar biodiesel $40 \%$ sebesar 7,13 Nm. Torsi maksimal penggunaan bahan bakar biodiesel $50 \%$ 
sebesar 7,15 Nm. Dari data hasil pengujian diperoleh Torsi rata - rata dihasilkan pada penggunaan bahan bakar biosolar murni menghasilkan Torsi rata - rata terbesar. Hasil penelitian tentang pengaruh penggunaan campuran bahan bakar biodiesel jelentah terhadap Torsi menunjukkan bahwa kualitas bahan bakar Biodiesel Dymetil Ester mempunyai kualitas lebih rendah dari pada kualitas bahan bakar Biosolar, hal ini dibuktikan baik pada campuran $30 \%, 40 \%$ dan $50 \%$ Biodiesel pada bahan bakar Biosolar Torsi motor yang dihasilkan menurun.

\section{Hubungan Sfc dan Beban}

Berdasarkan tabel hasil pengujian Sfc sebagai pengujian beban pada pemanasan bahan bakar $95^{\circ} \mathrm{C}$ dapat dibuat grafik hubungan $\mathrm{Sfc}$ dan beban pengujian, sebagai berikut :

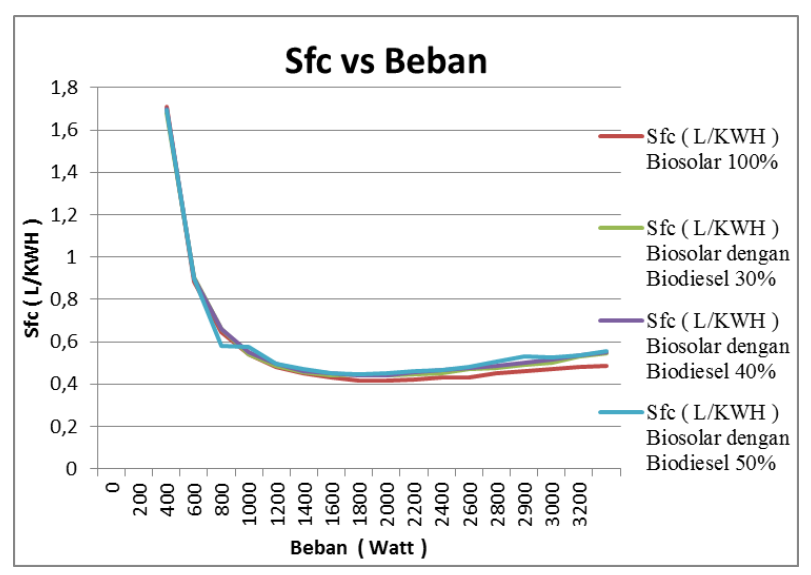

Gambar 4. Grafik Hubungan Sfc dan Beban

Berdasarkan grafik hasil pengujian pada variasi bahan bakar dengan pemanasan bahan bakar $95^{\circ} \mathrm{C}$ prosentase dengan biodiesel jelantah pada bahan bakar dapat menghasilkan Sfc minimal sebagai berikut :

a. Pada pengujian bahan bakar biosolar murni menghasilkan Sfc rata - rata sebesar 0,56 L/KWH.

b. Pada pengujian biosolar dengan variasi biodiesel jelantah 30\% menghasilkan Sfc rata - rata sebesar $0,58 \mathrm{~L} / \mathrm{KWH}$. Pada prosentase $30 \%$ terjadi kenaikan Sfc yang dihasilkan sebesar 3,817\%. Konsumsi bahan bakar yang lebih tinggi pada pengujian campuran bahan bakar biodiesel disebabkan oleh menurunnya kualitas bahan bakar.

c. Pada pengujian biosolar dengan variasi biodiesel jelantah $40 \%$ menghasilkan Sfc rata - rata sebesar $0,59 \mathrm{~L} / \mathrm{KWH}$. Pada prosentase $40 \%$ terjadi kenaikan Sfc yang dihasilkan sebesar 5,155\%. Konsumsi bahan bakar yang lebih tinggi diakibatkan karena banyaknya prosentase campuran bahan bakar biodiesel yang mengakibatkan menurunnya kualitas bahan bakar.

d. Pada pengujian biosolar dengan variasi biodiesel jelantah $50 \%$ menghasilkan Sfc rata - rata sebesar 0,59 L/KWH. Pada prosentase 50\% terjadi kenaikan Sfc yang dihasilkan sebesar 5,397\%. Konsumsi bahan bakar yang lebih tinggi diakibatkan karena banyaknya jumlah campuran bahan bakar biodiesel yang mengakibatkan menurunnya kualitas bahan bakar.

\section{Pembahasan}

Berdasarkan grafik hubungan Sfc dan Beban diperoleh Sfc rata - rata pada penggunaan bahan bakar biosolar murni sebesar $0,56 \mathrm{~L} / \mathrm{KWH}$. Sfc rata - rata penggunaan bahan bakar biodiesel jelantah $30 \%$ sebesar $0,58 \mathrm{~L} / \mathrm{KWH}$. Pada penggunaan bahan bakar biodiesel $40 \%$ sebesar $0,59 \mathrm{~L} / \mathrm{KWH}$. Sfc rata - rata penggunaan bahan bakar biodiesel 50\% sebesar 0,59 L/KWH. Dari data hasil pengujian diperoleh Sfc rata - rata minimum dihasilkan pada penggunaan bahan bakar biosolar murni. Hasil penelitian tentang pengaruh penggunaan campuran bahan bakar biodiesel jelentah terhadap Sfc menunjukkan bahwa kualitas bahan bakar Biodiesel Dymetil Ester mempunyai kualitas lebih rendah dari pada kualitas bahan bakar Biosolar, hal ini dibuktikan baik pada campuran $30 \%$, $40 \%$ dan $50 \%$ Biodiesel pada bahan bakar Biosolar Sfc motor yang dihasilkan lebih besar.

\section{B. PENUTUP}

\section{Kesimpulan}

Berdasarkan analisis yang telah diuraikan pada pembahasan sebelumnya, dan dengan mengacu pada perumusan masalah maka dapat disimpulkan beberapa hal sebagai berikut :

1. Berdasarkan hasil penelitian penambahan bahan bakar biodiesel jelantah pada bahan bakar biosolar terhadap Daya diperoleh kesimpulan sebagai berikut Daya rata - rata pada penggunaan bahan bakar solar murni sebesar 1131,32 Watt. Pada penggunaan bahan bakar solar ditambah bahan bakar biodiesel $30 \%$ sebesar 1127,37 Watt. Pada penggunaan bahan bakar solar ditambah biodiesel 40\% sebesar 1119,89 Watt. Pada penggunaan bahan bakar solar ditambah biodiesel 50\% sebesar 1122,74 Watt. Penambahan bahan bakar biodiesel jelantah mengakibatkan menurunnya kualitas bahan bakar sehingga Daya yang dihasilkan menurun.

2. Berdasarkan hasil penelitian penambahan bahan bakar biodiesel jelantah pada bahan bakar biosolar terhadap Torsi diperoleh kesimpulan sebagai berikut Torsi rata - rata pada penggunaan bahan bakar solar murni sebesar 7,21 Nm. Pada penggunaan bahan bakar solar ditambah bahan bakar biodiesel $30 \%$ sebesar 7,18 Nm. Pada penggunaan bahan bakar solar ditambah biodiesel $40 \%$ sebesar 7,13 Nm. Pada penggunaan bahan bakar solar ditambah biodiesel $50 \%$ sebesar 7,15 Nm. Penambahan campuran bahan bakar biodiesel mengakibatkan menurun kualitas bahan bakar sehingga Torsi yang dihasilkan menurun.

3. Berdasarkan hasil penelitian penambahan bahan bakar biodiesel jelantah pada bahan bakar biosolar terhadap Sfc diperoleh kesimpulan sebagai berikut Sfc rata - rata pada penggunaan bahan bakar solar murni sebesar 0,56 L/KWH. Pada penggunaan bahan bakar solar ditambah bahan bakar biodiesel $30 \%$ sebesar 0,58 L/KWH. Pada penggunaan bahan bakar solar ditambah biodiesel $40 \%$ sebesar $0,59 \mathrm{~L} / \mathrm{KWH}$. Pada penggunaan bahan bakar solar ditambah biodiesel $50 \%$ sebesar $0,59 \mathrm{~L} / \mathrm{KWH}$. Penambahan 
bahan bakar biodiesel mengakibatkan kualitas bahan bakar menurun sehingga Sfc yang dihasilkan lebih besar.

\section{Saran}

1. Bagi pemilik kendaraan bermotor diesel perubahan pada penelitian ini dapat digunakan sebagai perubahan untuk menghasilkan performan kendaraan yang lebih baik dengan perubahan kecil.

2. Bagi pemilik kendaraan bermotor diesel perubahan pada penelitian ini dapat digunakan sebagai literatur untuk merubah bahan bakar biosolar dengan biodiesel karena menghasilkan Daya, Torsi dan Sfc yang tidak berbeda jauh dari bahan bakar biosolar dan mempunyai nilai ekonomis yang lebih baik dibandingkan biosolar.

3. Pada penelitian selanjutnya sebaiknya pada tiap-tiap bahan bakar yang dilakukan pemanasan dilakukan pengujian kekentalan, agar lebih terukur.

\section{DAFTAR PUSTAKA}

[1] Rahardjo Tirtoatmodjo, "Peningkatan Unjuk Kerja Motor Diesel dengan Penambahan Pemanas Solar" Universitas Kristen Petra, vol.1, No.2, pp.127-133, 1999.

[2] Bambang Susilo, "Uji biodiesel dari minyak goreng bekas untuk bahan bakar motor diesel", Staf pengajar jurusan teknik pertanian fakultas teknologi pertanian Universitas Brawijaya, 2006.

[3] Darnoko dan Cheryan, "Kinetika Reaksi Transesterifikasi Minyak Goreng Bekas" Universitas Indonesia, 2007.

[4] John Dixon, "Modern Diesel Technology Preventive Maintenance and Ispection', Delmar Cengage, New York, 2010.

[5] John B. Heywood, "Internal Combustion Engine Fundamentals". McGraw- Hill,inc, 1976.

[6] Grahan, "Pengaruh Pemanasan Bahan Bakar terhadap Unjuk Kerja Motor Diesel Silinder Tunggal Berbahan Bakar biodiesel". STT Wiworotomo Purwokerto, 2012.

[7] Eka Bagus Syahrudin, "Analisa Pengaruh Penggunaan Campuran Bahan Bakar Solar Dengan Minyak Goreng Bekas Terhadap Unjuk Kerja Motor Diesel", STT Wiworotomo Purwokerto, 2014.

[8] Isalmi Aziz, "Uji performance motor diesel menggunakan biodiesel dari minyak goreng bekas "UIN Syarif Hidayatullah", Jakarta, 2008.

[9] Muammar, "Pengaruh Variasi Pemanasan Bahan Bakar Pada Timing Injection Advanced $65^{\circ}$ Terhadap Unjuk Kerja Motor Diesel Silinder Tunggal Berbahan Bakar Bio Solar", Sekolah Tinggi Teknik Wiworotomo Purwokerto, 2014.

[10] Tim Fakultas Teknik, "Teknik Dasar Motor Diesel”, Universitas Negeri Yogyakarta", hlm 9 - 18, 2003.

[11] Arifin Nur" Performance characteristic of indirect diesel engine fuelled with diesel-bioethanol using Uniplot software", Energi Procedia 167-176, ICSEEA, 2014. 